Article

\title{
Interannual Relationship between ENSO and Atlantic Storm Track in Spring Modulated by the Atlantic Multidecadal Oscillation
}

\author{
Chenfei Liao ${ }^{1,2} \oplus$, Haiming $X u^{1,2, * \mathbb{C}}$, Jiechun Deng ${ }^{1,2}$ and Leying Zhang ${ }^{3}$ \\ 1 Key Laboratory of Meteorological Disaster, Ministry of Education (KLME)/Joint International Research \\ Laboratory of Climate and Environment Change (ILCEC)/Collaborative Innovation Center on Forecast and \\ Evaluation of Meteorological Disasters (CIC-FEMD), Nanjing University of Information Science \& \\ Technology, Nanjing 210044, China; fionaliaocf@163.com (C.L.); jcdeng@nuist.edu.cn (J.D.) \\ 2 School of Atmospheric Sciences, Nanjing University of Information Science \& Technology, \\ Nanjing 210044, China \\ 3 Joint Innovation Center for Modern Forestry Studies, College of Biology and Environment, \\ Nanjing Forestry University, Nanjing 210037, China; zhangleyingzi@126.com \\ * Correspondence: hxu@nuist.edu.cn; Tel.: +86-25-5873-1166
}

Received: 13 September 2018; Accepted: 24 October 2018; Published: 25 October 2018

check for updates

\begin{abstract}
It has been well documented that storm track activity are closely related to the weather and short-term climate variability in the extratropics, which is affected by sea surface temperature anomalies over the tropical eastern Pacific Ocean. Interannual relationship between the El Niño-Southern Oscillation (ENSO) and the Atlantic storm track (AST) in spring modulated by the Atlantic multidecadal oscillation (AMO) was investigated using reanalysis data and model simulations in this study. The meridional displacement of the AST is significantly correlated with ENSO during negative AMO phase, while no significant relationship is found during positive AMO phase. This may be due to the difference of 500-hPa geopotential height anomalies induced by ENSO in different AMO phases. For an El Niño event during the negative AMO phase, an anomalous 500-hPa wave train propagates eastward across the North American continent, with positive height anomalies at the high latitudes, extending from South Canada to Newfoundland. Thus, easterly wind anomalies appear over central North America, upstream of the negative AST anomaly. Accordingly, the local eddy growth rate (EGR) and baroclinic energy conversion (BC) are obviously reduced, which weaken (strengthen) the southern (northern) part of the climatological AST. As a result, the AST is shifted northward significantly. During the positive AMO phase, the ENSO-related anomalous wave train at $500 \mathrm{hPa}$ only propagates northeastward and is largely suppressed over Northwest Canada, with positive height anomalies confined to the northwest of North America. Therefore, no significant changes of the westerly jet, EGR and $\mathrm{BC}$ are found in the upstream region of the AST, and the meridional location of the AST generally remains unchanged. Most previous studies investigate AST variabilities in winter, and few focus on AST in spring. This work may be helpful in understanding more about the interannual and interdecadal variations of springtime AST and in further studying the weather and short-term climate changes caused by AST.
\end{abstract}

Keywords: Atlantic multidecadal oscillation; decadal modulation; El Niño-Southern Oscillation; Atlantic storm track; spring 


\section{Introduction}

Generally, the storm track is referred to the most active region of the synoptic-scale transient eddies in the mid latitudes. Both the intensity and location of the storm track are closely related to the weather and short-term climate variability in the extratropics [1-3]. They can influence not only global circulation by transporting moisture mass, sensible heat and zonal angular momentum poleward $[4,5]$, but also the hydrological cycle through anomalous evaporation from warm ocean surface and precipitation [6].

The Atlantic storm track (AST) is one of the most active storm tracks in the Northern Hemisphere $(\mathrm{NH})$. It varies at different timescales, including seasonal $[7,8]$, interannual $[9,10]$ and interdecadal timescales $[3,11]$. On the seasonal timescale, the AST shifts equatorward with the jet stream from fall to mid-winter, reaching its maximum amplitude [7,8], and shifts poleward after January [7]. For the decadal timescale, Ebisuzaki and Chelliah [12] pointed out that the AST was much weaker in the 1960s than in recent decades. Graham and Diaz [13] suggested that the frequency and intensity of extreme cyclones over the Atlantic basins increased over the second half of the 20th century. In terms of interannual timescale, it is shown that the AST is closely related to the atmospheric circulations over the mid-to-high latitudes, e.g., the extratropical North Atlantic Oscillation (NAO) and the Arctic Oscillation (AO). Riviere and Orlanski [14] pointed out that the AST is strengthened during positive NAO. Nie et al. [15] found that the AST is shifted northward and significantly strengthened during winter with a strong positive AO. He et al. [16] found that the interannual variability of the AST is associated with the El Niño-Southern Oscillation (ENSO), i.e., the AST is weakened and extends westward and equatorward in winter during an El Niño event; and the opposite happens during a La Niña event. Previous studies mostly focus on the AST variability in winter, while the springtime AST also has significant influence on precipitation in surrounding areas [17]. Thus, exploration on the variation of the springtime AST is necessary and meaningful.

He et al. [16] demonstrated that ENSO and AST have a significant relationship in winter. Although the intensity of ENSO is relatively weaker in spring, it can still make great contributions to the atmospheric circulation [18-20]. Especially, Krishnamurthy et al. [18] found that ENSO in spring has a critical impact on the North America low-level jet via the Walker and Hadley circulations. Thus, whether ENSO in spring also has significant influence on the AST activity deserves further study. This may be helpful in understanding more about the interannual and interdecadal variations of the springtime AST and in further studying the weather and short-term climate changes caused by the AST. Moreover, since both ENSO and AST have significant decadal variability $[3,11,21]$, whether the interannual relationship between ENSO and springtime AST exhibits decadal variability needs to be studied.

The Atlantic multidecadal oscillation (AMO) is a large-scale climate signal, characterized by sea surface temperature (SST) anomalies sustained in the North Atlantic with a long periodicity of 50-70 years, which plays an important role in the NH climate [22-25]. In addition, the AMO can affect ENSO decadal variability [26]. A positive AMO could result in suppressed ENSO through the "atmospheric bridge" [26-28], implying that the AMO may regulate the interannual relationship between ENSO and springtime AST in different decades. Therefore, we explored decadal change of the interannual relationship between ENSO and springtime AST, and the possible role of the AMO in this process.

The rest of this paper is organized as follows. Section 2 introduces the data and methods used in this study. In Section 3, we analyze the changing interannual relationship between ENSO and springtime AST during different phases of the AMO and explore possible roles of the AMO in the decadal change between ENSO and AST. Conclusion are provided in Section 4. 


\section{Data and Methodology}

\subsection{Reanalysis Data and Methodology}

The daily atmospheric data from the National Center for the Environment Prediction/the National Center for the Atmospheric Research (NCEP/NCAR) global reanalysis dataset, version 1 (NCEP-1) covering from 1948 to present [29] were used, which include winds, air temperature and geopotential height. The horizontal resolution of the data is $2.5^{\circ} \times 2.5^{\circ}$. The monthly SST data at $2^{\circ} \times 2^{\circ}$ resolution from the National Oceanic and Atmospheric Administration (NOAA) Extended Reconstructed SST analysis, version 5 (ERSST v5) [30] were also used in this study. For consistency, all variables covered the period from 1948 to 2017. In this study, spring refers to the period of March, April and May (MAM).

The storm track activity is defined as the 2.5-6.0-day band-pass-filtered geopotential height variance $\left(\overline{Z^{\prime 2}}\right)$ at $500 \mathrm{hPa}$ [31]. The Niño3.4 index is defined as the normalized anomalies of area-averaged SST in spring over the region of $\left(120^{\circ}-170^{\circ} \mathrm{W}, 5^{\circ} \mathrm{S}-5^{\circ} \mathrm{N}\right)$ [32], which is used to describe the spring ENSO intensity. The AMO index is defined as the area-averaged SST anomalies over the region of $\left(0^{\circ}-80^{\circ} \mathrm{W}, 0^{\circ}-70^{\circ} \mathrm{N}\right)$ [33]. The positive (negative) phase of the AMO refers to the period of the positive (negative) smoothed (i.e., 11-year low-pass-filtered) AMO index in spring. To reveal the interannual relationship between ENSO and AST, an 11-year high-pass filter is applied to the associated variables and indexes, including horizontal winds, geopotential height, the storm track activity, and the Niño3.4 index. The three filtering techniques mentioned above (i.e., 2.5-6-day band-pass filter, 11-year low-pass filter and 11-year high-pass filter) are all Lanczos filter [34], which is widely used to extract signals at a specific range of frequencies from a given data sequence in the meteorological field [35-38]. To avoid possible boundary distortion, the first and last five years of the 11-year high/low-pass filtered variables were removed according to Duchon [34]. Thus, the results of the interannual relationship between ENSO and AST only covers the period of 1953-2012. Two positive AMO phases (1953-1964 and 1996-2012) and one negative AMO phase (1965-1995) were found in this period.

The baroclinic processes are important for the development of storm track activity $[3,39]$. The maximum eddy growth rate (EGR) is an effective measure of atmospheric baroclinic instability [40], which is defined as follows:

$$
E G R=0.31 \frac{f}{N}\left|\frac{\partial u}{\partial Z}\right|
$$

where $f$ is the Coriolis parameter, $N$ is the Brunt-Väisälä frequency, $Z$ is geopotential height, and $u$ is zonal wind.

The baroclinic energy conversion (BC) plays an important role in generating high-frequency atmospheric eddies [41]. According to Cai et al. [41], the energy conversion from mean available potential energy (MAPE) to eddy available potential energy (EAPE; $B C_{a}$ ) and from the eddy available potential energy to eddy kinetic energy $\left(\mathrm{EKE} ; B C_{b}\right)$ are given by:

$$
\begin{aligned}
B C_{a}=-C_{1}\left(\frac{P_{0}}{P}\right)^{\frac{R}{C_{P}}} & \left(-\frac{d \theta}{d p}\right)^{-1}\left(\overline{u^{\prime} T^{\prime}} \frac{\partial \bar{T}}{\partial x}+\overline{v^{\prime} T^{\prime}} \frac{\partial \bar{T}}{\partial y}\right) \\
B C_{b} & =-C_{1}\left(\overline{\omega^{\prime} T^{\prime}}\right) \\
C_{1} & =\left(\frac{P_{0}}{P}\right)^{\frac{C_{V}}{C_{P}}} \frac{R}{g}
\end{aligned}
$$

where $P_{0}$ is $1000 \mathrm{hPa}, P$ is the pressure (hPa), $g$ is the acceleration of gravity, $R$ is the gas constant for dry air, $C_{p}\left(C_{v}\right)$ is the specific heat of dry air at the constant pressure (volume), and $\theta$ indicates potential temperature. The overbar represents the climatological mean, and the prime represents transient parts calculated by the 2.5-6.0-day band-pass filter. 
The wave activity flux (WAF) defines the tendency of wave energy propagation. Wave energy propagation is analyzed by applying the WAF defined by Takaya and Nakamura [42]. The horizontal WAF may be expressed as:

$$
W=\frac{P \cos \varphi}{2000|U|}\left\{\begin{array}{l}
\frac{U}{a^{2} \cos ^{2} \varphi}\left[\left(\frac{\partial \varphi^{\prime}}{\partial \lambda}\right)^{2}-\psi^{\prime} \frac{\partial^{2} \psi^{\prime}}{\partial \lambda^{2}}\right]+\frac{V}{a^{2} \cos \varphi}\left[\frac{\partial \psi^{\prime}}{\partial \lambda} \frac{\partial \psi^{\prime}}{\partial \varphi}-\psi^{\prime} \frac{\partial^{2} \psi^{\prime}}{\partial \lambda \partial \varphi}\right] \\
\frac{U}{a^{2} \cos \varphi}\left[\frac{\partial \psi^{\prime}}{\partial \lambda} \frac{\partial \psi^{\prime}}{\partial \varphi}-\psi^{\prime} \frac{\partial^{2} \psi^{\prime}}{\partial \lambda \partial \varphi}\right]+\frac{V}{a^{2}}\left[\left(\frac{\partial \psi^{\prime}}{\partial \varphi}\right)^{2}-\psi^{\prime} \frac{\partial^{2} \psi^{\prime}}{\partial \varphi^{2}}\right]
\end{array}\right.
$$

where $a$ is the earth's radius, $\psi^{\prime}$ is the perturbation geostrophic streamfunction, $U=(U, V)$ is the horizontal basic flow velocity, and $(\varphi, \lambda)$ are latitude and longitude, respectively.

\subsection{Model Introduction}

The Community Atmosphere Model version 5.1 (CAM5.1) of the Community Earth System Model version 1.0.3 (CESM1.0.3) is employed to further analyze the interannual relationship between ENSO and AST in spring modulated by the AMO. CAM5.1 is an atmospheric general circulation model originally developed by the NCAR. It can be used as a standalone model or as the atmospheric component coupled with other models in the CESM [43]. CAM5.1 used in this study has a horizontal resolution of $1.9^{\circ} \times 2.5^{\circ}$ and a hybrid vertical coordinate with 30 levels, including a rigid lid at $3.643 \mathrm{hPa}$.

We performed a control experiment (CTRL) and four sensitivity experiments. The CTRL is forced by climatological monthly mean SST during 1850 to 2010. Four sensitivity experiments were performed with different ocean surface boundary conditions (Table 1$)$. The North Atlantic $\left(70^{\circ} \mathrm{W}-0,0-70^{\circ} \mathrm{N}\right) \mathrm{SST}$ anomalies (SSTA) regressed onto the AMO index are deemed as the positive AMO SSTA (AMO+), and the tropical Pacific $\left(170^{\circ} \mathrm{E}-75^{\circ} \mathrm{W}, 20^{\circ} \mathrm{S}-20^{\circ} \mathrm{N}\right)$ SSTA regressed onto the Niño3.4 index are the El Niño SSTA (El Niño); and the corresponding opposite signs are the negative AMO SSTA (AMO-) and La Niña SSTA (La Niña), respectively. In the sensitivity experiments, the AMO+/AMO- and El Niño/La Niña SSTA are imposed in pairs on the climatological monthly mean SST from February to June (Table 1), including AMO+/El Niño, AMO+/La Niña, AMO-/El Niño, and AMO-/La Niña, as shown in Figure 1. Each experiment was integrated for 20 years, and the results from the last 10 years were analyzed. In one 20-year sensitivity simulation, the specific AMO-related SSTA is imposed to climatological mean SST over the North Atlantic as the boundary condition for each model year, and the imposed SSTA does not vary yearly during the 20 model years. Thus, differences between AMO+/El Niño (AMO-/El Niño) and AMO+/La Niña (AMO-/La Niña) can be regarded as the impact of ENSO on the spring AST in a positive (negative) AMO phase. In addition, Ruprich-Robert et al. [44] investigated the climate impacts of the Atlantic multidecadal variability based on 10-year model simulation. Thus, the comparative analysis of four 20-year sensitivity experiments was used to explore the AMO decadal influences.

Table 1. List of the perturbed-SST experiments.

\begin{tabular}{|c|c|}
\hline Experiments & Description of the SST Perturbation \\
\hline $\mathrm{AMO}+/$ El Niño & $\begin{array}{l}\text { Positive SST anomalies (SSTA) regressed onto the AMO index are imposed over the } \\
\text { North Atlantic }\left(70^{\circ} \mathrm{W}-0,0-70^{\circ} \mathrm{N}\right) \text {, and positive SSTA regressed onto the Niño3.4 index } \\
\text { are also imposed over the tropical Pacific }\left(170^{\circ} \mathrm{E}-75^{\circ} \mathrm{W}, 20^{\circ} \mathrm{S}-20^{\circ} \mathrm{N}\right)\end{array}$ \\
\hline $\mathrm{AMO}+/ \mathrm{La}$ Niña & Same as in AMO+/El Niño, but with negative SSTA imposed over the tropical Pacific \\
\hline AMO-/El Niño & Same as in AMO+/El Niño, but with negative SSTA imposed over the North Atlantic \\
\hline
\end{tabular}


(a)AMO+/El niño
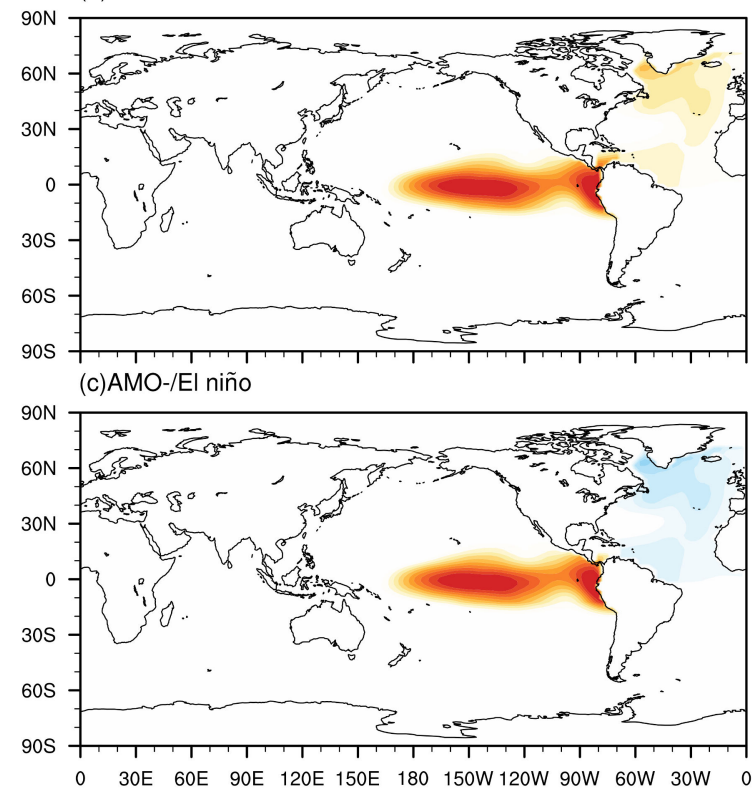

(b)AMO+/La niña

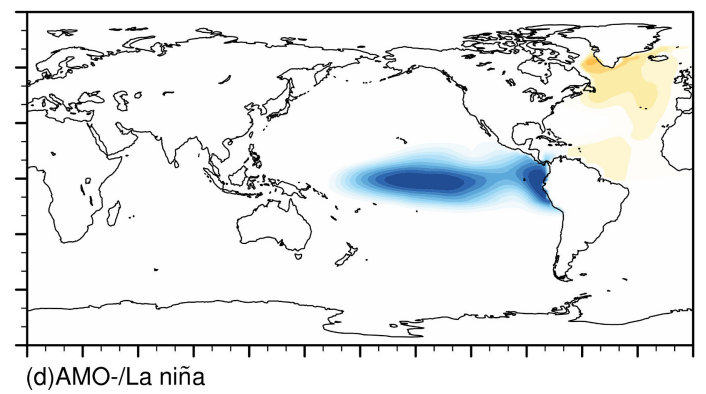

$\begin{array}{lllllll}-0.9 & -0.6 & -0.3 & 0 & 0.3 & 0.6 & 0.9\end{array}$

Figure 1. Spatial distribution of the SST anomalies (shading; units: ${ }^{\circ} \mathrm{C}$ ) in February imposed on the: (a) AMO+/El Niño; (b) AMO-/La Niña; (c) AMO-/El Niño; and (d) AMO-/La Niña experiments.

\section{Results and Discussion}

\subsection{Result of Atmospheric Reanalysis}

Figure 2 shows the first two Empirical Orthogonal Function (EOF) [45] modes of the spring storm track activity, together with the normalized principle component (PC) time series of the corresponding EOF modes. The first and second EOF modes account for $22.4 \%$ and $13.6 \%$ of the total variance, respectively; and both can be well separated from the other eigenvalues based on the criterion of North et al. [46]. The center of the storm track activity in the first mode (EOF1, Figure 2a) extends from the Great Lakes to the northeast of the Atlantic Ocean, and coincides with the climatological AST center (black contours in Figure 2a). This suggests that the normalized PC1 can signify the intensity of the AST (Figure 2c). Moreover, the spatial distribution of EOF1 is similar to that in winter of Lee et al. [47]. The second mode (EOF2) of the AST manifests a dipole structure with a positive anomaly over the northern Sargasso Sea and a negative anomaly to the south of Iceland, which are located south and north of the climatological AST, respectively (Figure 2b). Thus, the normalized PC2 can represent the meridional displacement of the AST (Figure 2d). The normalized PC1 and PC2 can thus well describe the interannual variability of the intensity and meridional location of the AST, respectively.

According to the EOF1, the intensity index of the AST $\left(\mathrm{I}_{\mathrm{AST}}\right.$; blue line in Figure $\left.2 \mathrm{c}\right)$ is further defined as the normalized anomalies of area-averaged $\overline{Z^{\prime 2}}$ in spring over the key area of $\left(17^{\circ}-78^{\circ} \mathrm{W}\right.$, $40^{\circ}-59^{\circ} \mathrm{N}$; the regular blue box in Figure 2a). The correlation coefficient between $\mathrm{I}_{\mathrm{AST}}$ and PC1 is 0.99 , significant at the $95 \%$ confidence level. Thus, a higher (lower) $\mathrm{I}_{\mathrm{AST}}$ indicates a stronger (weaker) AST. On the other hand, the positive center $\left(35^{\circ}-65^{\circ} \mathrm{W}, 37^{\circ}-48^{\circ} \mathrm{N}\right.$; the regular blue box in Figure $2 \mathrm{~b}$ ) and negative center $\left(4^{\circ}-44^{\circ} \mathrm{W}, 54^{\circ}-65^{\circ} \mathrm{N}\right.$; the regular red box in Figure $\left.2 \mathrm{~b}\right)$ of the EOF2 mode are selected as the key areas for the meridional location of the AST, respectively. The location index of the AST $\left(\mathrm{L}_{\mathrm{AST}}\right)$ is defined as the normalized difference between the area-averaged $\overline{\mathrm{Z}^{2}}$ over the positive center in the south and that over the negative center in the north. The correlation coefficient between $\mathrm{L}_{\mathrm{AST}}$ and PC2 is 0.91 , significant at the $95 \%$ confidence level. Accordingly, a positive (negative) $\mathrm{L}_{\mathrm{AST}}$ 
indicates a southward (northward) shifted AST. Thus, $\mathrm{I}_{\mathrm{AST}}$ and $\mathrm{L}_{\mathrm{AST}}$ can well represent the interannual variability of the intensity and the meridional location of the AST, respectively.
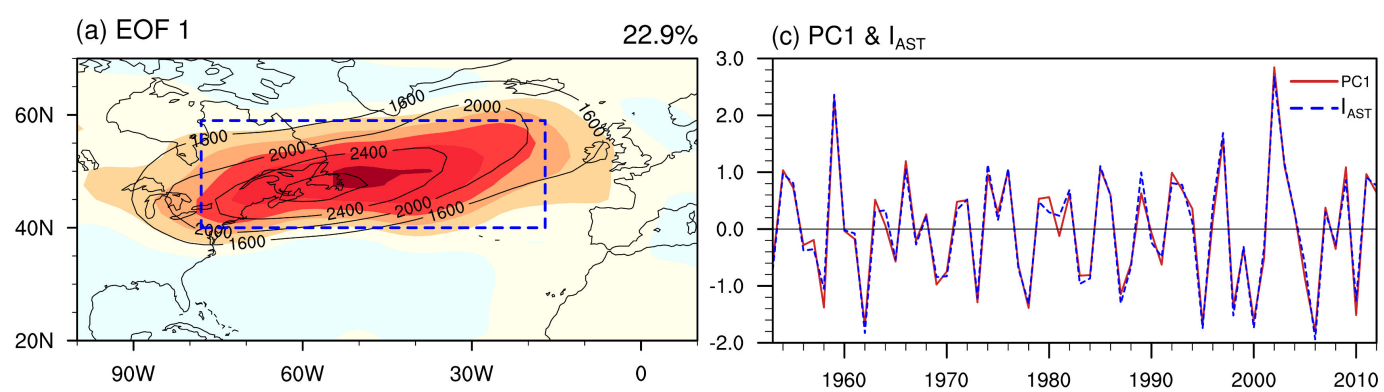

(b) EOF 2
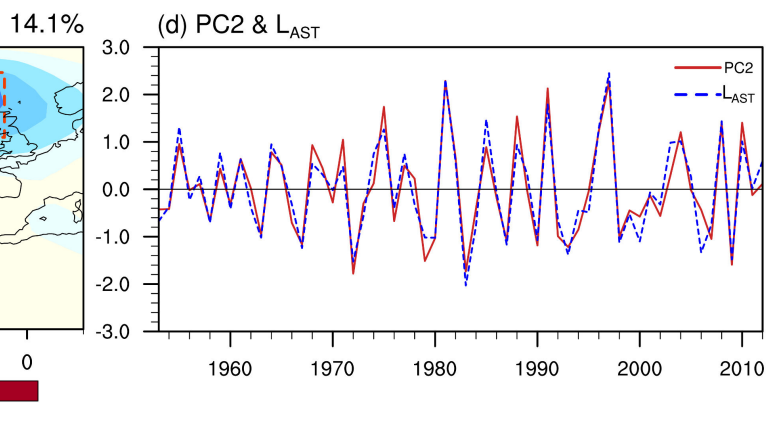

Figure 2. Spatial patterns of (a) first and (b) second EOF modes of 500-hPa band-pass-filtered geopotential height variance $\overline{Z^{\prime 2}}$ (shading; units: $\mathrm{m}^{2}$ ) in spring during 1953-2012, and corresponding normalized time series (red solid curves) in (c,d), respectively. Blue dashed curves in (c,d) represent the intensity $\left(\mathrm{I}_{\mathrm{AST}}\right)$ and location $\left(\mathrm{L}_{\mathrm{AST}}\right)$ indexes of the AST, respectively. The spring climatological AST (contour; units: $\left.\mathrm{m}^{2}\right)$ is also plotted in $(\mathbf{a}, \mathbf{b})$.

To explore the interannual correlation between ENSO and springtime AST, we calculated the correlation coefficient between the Niño3.4 index and $\mathrm{I}_{\mathrm{AST}}\left(\mathrm{L}_{\mathrm{AST}}\right)$ during 1953-2012, which is -0.193 $(-0.378)$, insignificant (significant) at the $95 \%$ confidence level. This indicates that the AST is significantly shifted northward during an El Niño event, with little change of its intensity. Thus, we mainly focused on the interannual relationship between ENSO and the meridional location of the AST next, especially on its decadal variation. He et al. [16] suggested that the winter AST is significantly weakened and shifted westward and equatorward during an El Niño event. To confirm our results, the correlation between ENSO and AST in winter is calculated, which is consistent with He et al. [16]. This suggests that the correlation between ENSO and AST varies in winter and spring, which may be due to the relatively southward distribution of the circulation anomalies induced by the weakened ENSO in spring.

Figure 3 shows the 13-year-running-averaged correlations between the Niño3.4 index and $\mathrm{L}_{\mathrm{AST}}$. It can be seen that a considerably interdecadal change exists in the interannual relationship between ENSO and the meridional position of the AST. The negative correlation between the Niño3.4 index and $\mathrm{L}_{\mathrm{AST}}$ is relatively small before $\sim 1965$ and then gradually enhances until reaching its maximum around 1985. Moreover, this correlation is significant at the $95 \%$ confidence level from the 1970 s to the mid-1990s. However, the negative correlation largely decreases during the 1990s and even turns to positive in the 2000s. Interestingly, the decadal change of the correlation between the Niño3.4 index and $\mathrm{L}_{\mathrm{AST}}$ is in accordance with the phase of the AMO, namely, this correlation is significant (insignificant) when the AMO is in its negative (positive) phase. Furthermore, the scatterplot is used to present the relationship between ENSO and AST during different AMO phase (Figure 4). Clearly, a linear relationship is observed between the Niño3.4 index and $\mathrm{L}_{\mathrm{AST}}$ during the negative AMO phase, and the linear regression coefficient approximately equals -0.52 , which exceeds the $95 \%$ confidence level. However, the linear regression coefficient only equals to -0.14 during the positive AMO phase. 
Therefore, the interannual relationship between ENSO and the meridional location of the AST exhibits significant decadal variation, i.e., the AST is significantly shifted northward during an El Niño event in the negative AMO phase, but not in the positive AMO phase.

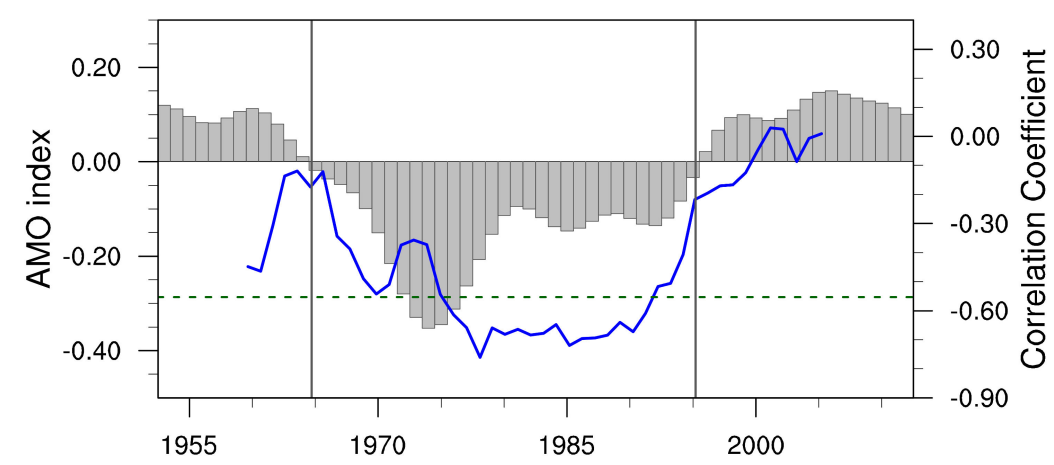

Figure 3. The 11-year low-pass-filtered AMO index (bar) and 13-year sliding correlation coefficient between Niño3.4 index and $\mathrm{L}_{\mathrm{AST}}$ (blue curve) in spring during 1953-2012. The green dashed line indicates the correlation coefficient exceeding the $95 \%$ confidence level.

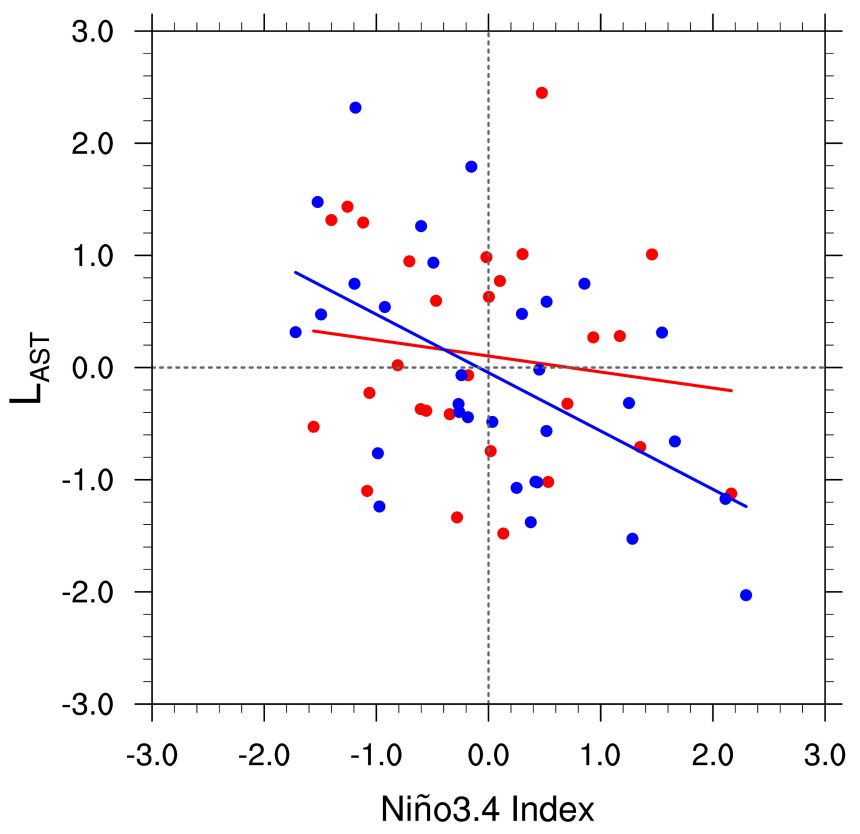

Figure 4. Scatterplot of the $\mathrm{L}_{\mathrm{AST}}$ as a function of the Niño3.4 index for positive (red dot) and negative (blue dot) AMO phases, together with the corresponding regression line.

Figure 5a displays the regression coefficient of the storm track activity onto the Niño3.4 index in spring during 1953-2012. Significant negative anomalies occur in the southern part of the AST, extending zonally across the whole Atlantic, and positive anomalies are located around the northeast of the AST. Accordingly, the AST is significantly shifted northward during an El Niño event, which is consistent with the negative correlation between the Niño3.4 index and $\mathrm{L}_{\mathrm{AST}}$. In the negative AMO phase (Figure $5 b$ ), there exists a spatial pattern similar to that of the whole study period, but with more marked positive anomalies in the north of the AST, suggesting that the AST would move further northward during an El Niño event in the negative AMO phase. In a sharp contrast, no significant anomaly is found in the positive AMO phase (Figure 5c), indicative of a weak relationship between ENSO and the meridional location of the AST. The results in other positive AMO phase (1953-1964) are similar and not shown for clarity. Overall, the interannual relationship between ENSO and the meridional location of the AST displays significant decadal variation, which is largely modulated by the AMO. 
(a) $1953-2012$

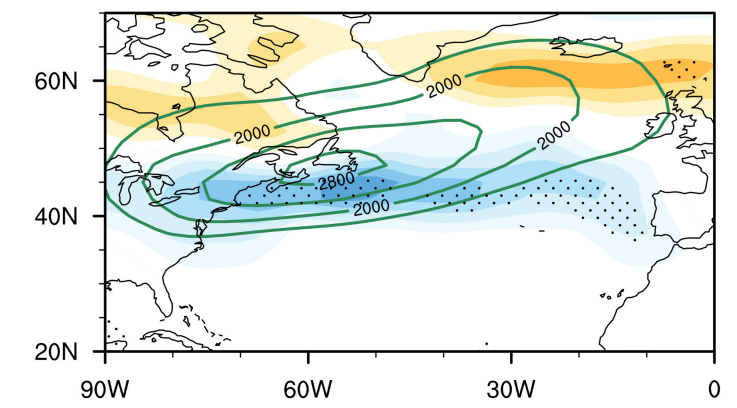

(b) 1965-1995(AMO-)

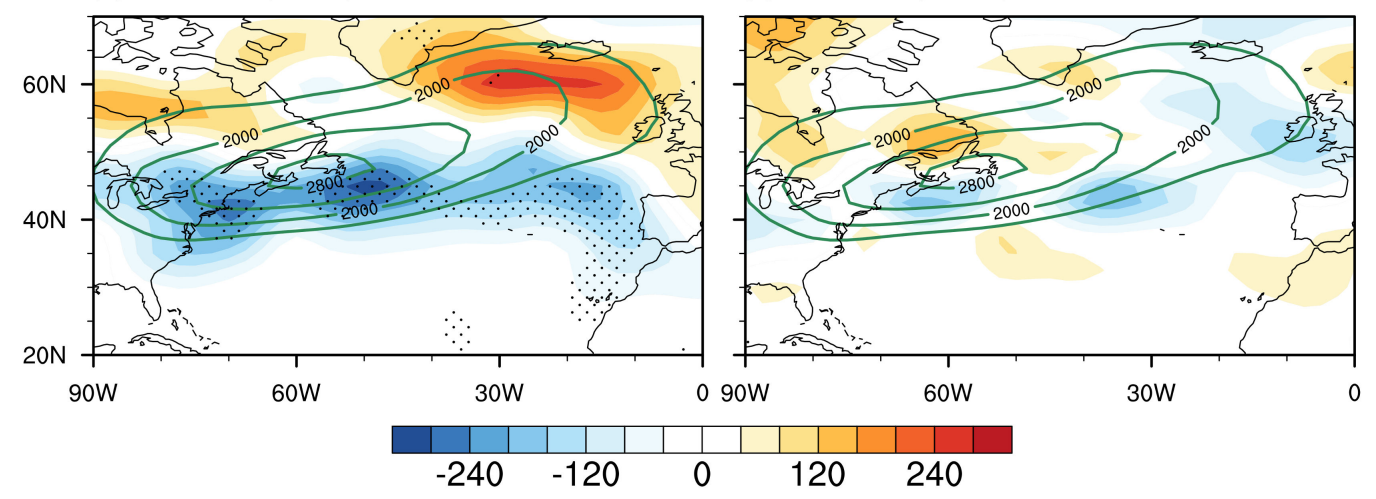

Figure 5. Regression coefficients of 500-hPa band-pass-filtered geopotential height variance $\overline{Z^{\prime 2}}$ (shading; units: $\mathrm{m}^{2}$ ) onto the Niño3.4 index in spring during: (a) 1953-2012; (b) 1965-1995 (AMO-); and (c) 1996-2012 (AMO+). Stippling represents significance exceeding the 95\% confidence level. The green contours represent the spring climatological AST.

Lau [2] and Metz [48] confirmed that storm track variance and covariance are related to changes in the mean flow. Figure 6a gives the regression coefficients of $500-\mathrm{hPa}$ geopotential height and $300-\mathrm{hPa}$ wind onto the Niño3.4 index in spring during 1953-2012. The spring 500-hPa wave train during an El Niño event is similar to the positive Pacific-North American (PNA) pattern, characterized by negative height anomalies reaching from the north of the Hawaiian Islands to southern United States and positive height anomalies over the tropics and South Canada, respectively. The analysis of the wave activity flux (WAF) can also signify the propagation of the wave train, following Takaya and Nakamura [42]. Corresponding to the wave train pattern in the whole study period (1953-2012), the wave energy is primarily originated around the Niño3.4 region, and propagates poleward and eastward to Northwest Canada before reaching southern North America. Thus, anomalous easterly winds appear over central North America, located in the upstream region of the anomalous positive center of the AST (Figure 2b). Previous studies showed that the storm track is usually located poleward and downstream of the upper-tropospheric jet $[7,49]$, and the intensity of the storm track tends to co-vary with that of the westerly jet stream. Thus, a negative jet anomaly in the mid latitudes during an El Niño event tends to induce weakened storm track activity in the south of the climatological AST, resulting in a northward shift of the AST. During the negative AMO phase, the propagation of the wave energy is similar to that in the whole study period, which crosses the mid latitudes of the North Atlantic. Specifically, the 500-hPa wave train in the negative AMO phase travels more eastward reaching Iceland and even the west coast of Europe. Geopotential height anomalies bear similarity to those in Figure 6a, but with much stronger positive height anomalies over Canada (Figure 6b). Moreover, this anomalous positive height extends eastward to Newfoundland and Iceland, accompanied by stronger easterly wind anomalies over central North America. Meanwhile, westerly wind anomalies appear in the high latitudes, extending eastward from West Canada to southern Greenland. Accordingly, the upper-tropospheric westerly jet stream is decreased in the mid latitudes 
and increased in the high latitudes, leading to a northward shifted jet stream. Thus, the storm track activity is weakened (strengthened) south (north) of the climatological AST, inducing a more marked northward displacement of the AST. However, the poleward-traveled wave energy in the positive AMO phase seems to be cut off after its origination, and only propagates northeastward until largely disappearing over Central Canada. As a result, positive height anomalies over South Canada are weak and only confined to the northwest of North America, together with weakened easterly wind anomalies to its south (Figure 6c). Correspondingly, the AST is shifted northward insignificantly during an El Niño event in the positive AMO phase. Besides, compared to the short-distance propagation in the positive AMO phase, the anomalous 500-hPa wave train can cross the entire North American continent in the negative AMO phase, which could influence the downstream storm track.

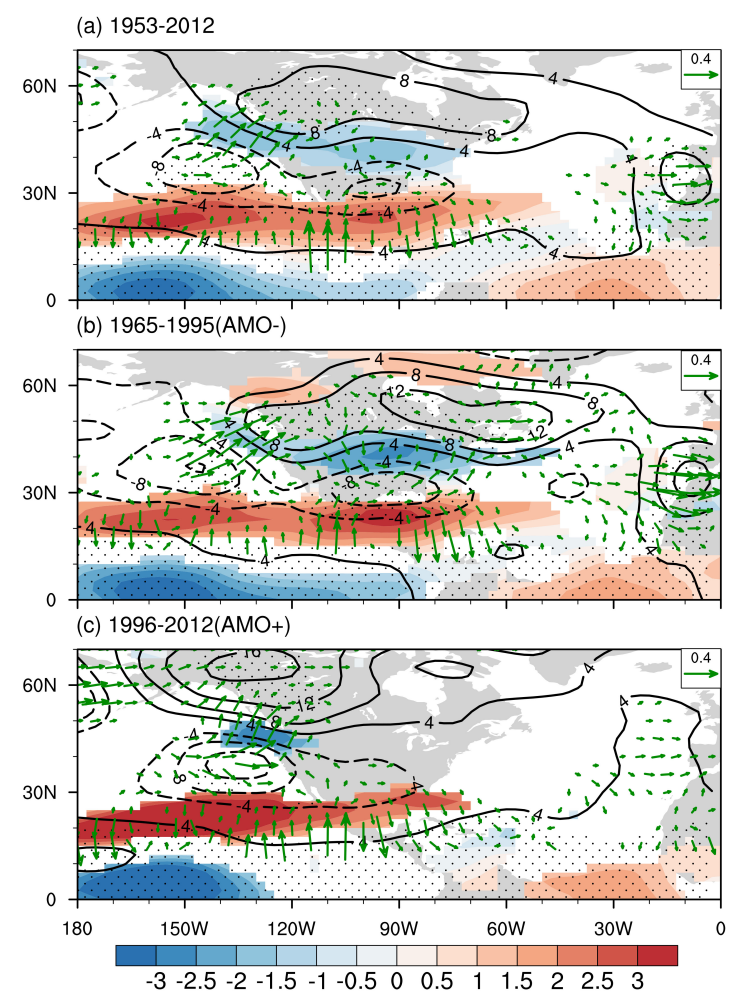

Figure 6. Regression coefficients of $500-\mathrm{hPa}$ geopotential height (contour; units: gpm) and 300-hPa zonal wind (shading; units: $\mathrm{m} / \mathrm{s}$ ) onto the Niño3.4 index in spring together with the corresponding wave activity flux (vector; units: $\mathrm{m}^{2} / \mathrm{s}^{2}$ ) during: (a) 1953-2012; (b) 1965-1995 (AMO-); and (c) 1996-2012 (AMO+). The solid and dashed contours represent positive and negative values, respectively, with an interval of $4 \mathrm{gpm}$; and the zero isoline is omitted for clarity. Stippling represents geopotential height anomalies exceeding the 95\% confidence level. Only zonal wind anomalies exceeding the $95 \%$ confidence level and the WAF with its amplitude exceeding $0.05 \mathrm{~m}^{2} / \mathrm{s}^{2}$ are plotted. Red and blue shading represents the positive and negative regression coefficients exceeding the $95 \%$ confidence level, respectively.

As shown in Figure 6, the geopotential height anomalies associated with ENSO exhibits a PNA-like pattern. Pinto et al. [50] demonstrated that the atmospheric baroclinicity over North America (upstream of the AST) is enhanced during the negative PNA. Since the atmospheric baroclinic instability provides baroclinic energy for the development of storm track [51], anomalous EGR associated with ENSO is further investigated. Figure 7 shows the regression coefficient of 700-hPa EGR onto the Niño3.4 index in spring. In terms of the whole study period (1953-2012), a negative EGR anomaly is principally found over central North America extending eastward to the northern Sargasso Sea during an El Niño event, and a positive anomaly in the high latitudes appears over the Davis Strait (Figure 7a), which are located upstream of the negative and positive AST anomalies (Figure 5a), respectively. This 
is consistent with the previous finding that storm track eddies often appear downstream of peak baroclinicity [51]. Although the geographical maximum of the baroclinic conversion is associated with that of the baroclinicity, it does not mean that baroclinic energy conversion is necessarily stronger for larger baroclinicity [7]. We further analyze the relationship between ENSO and BC. Figure 7d shows the regression coefficient of $\mathrm{BC}_{\mathrm{a}}$ from MAPE to EAPE onto the Niño3.4 index in spring, which is related to the horizontal eddy heat flux and mean temperature gradient. Compared to EGR (Figure 7a), the energy conversion is similarly negative over central North America and the Sargasso Sea, while no significant anomaly appears in the high latitudes. The anomalous $\mathrm{BC}_{\mathrm{b}}$ from EAPE to EKE related to ENSO is similar to the anomalous $\mathrm{BC}_{\mathrm{a}}$, but with a relatively weaker negative center (Figure $7 \mathrm{~g}$ ). Therefore, the local negative EGR over northern America tends to reduce the eddy energy obtained from the mean flow. The decreased eddy energy further contributes to the weakened storm track south of the AST, corresponding to the northward shift of the AST.
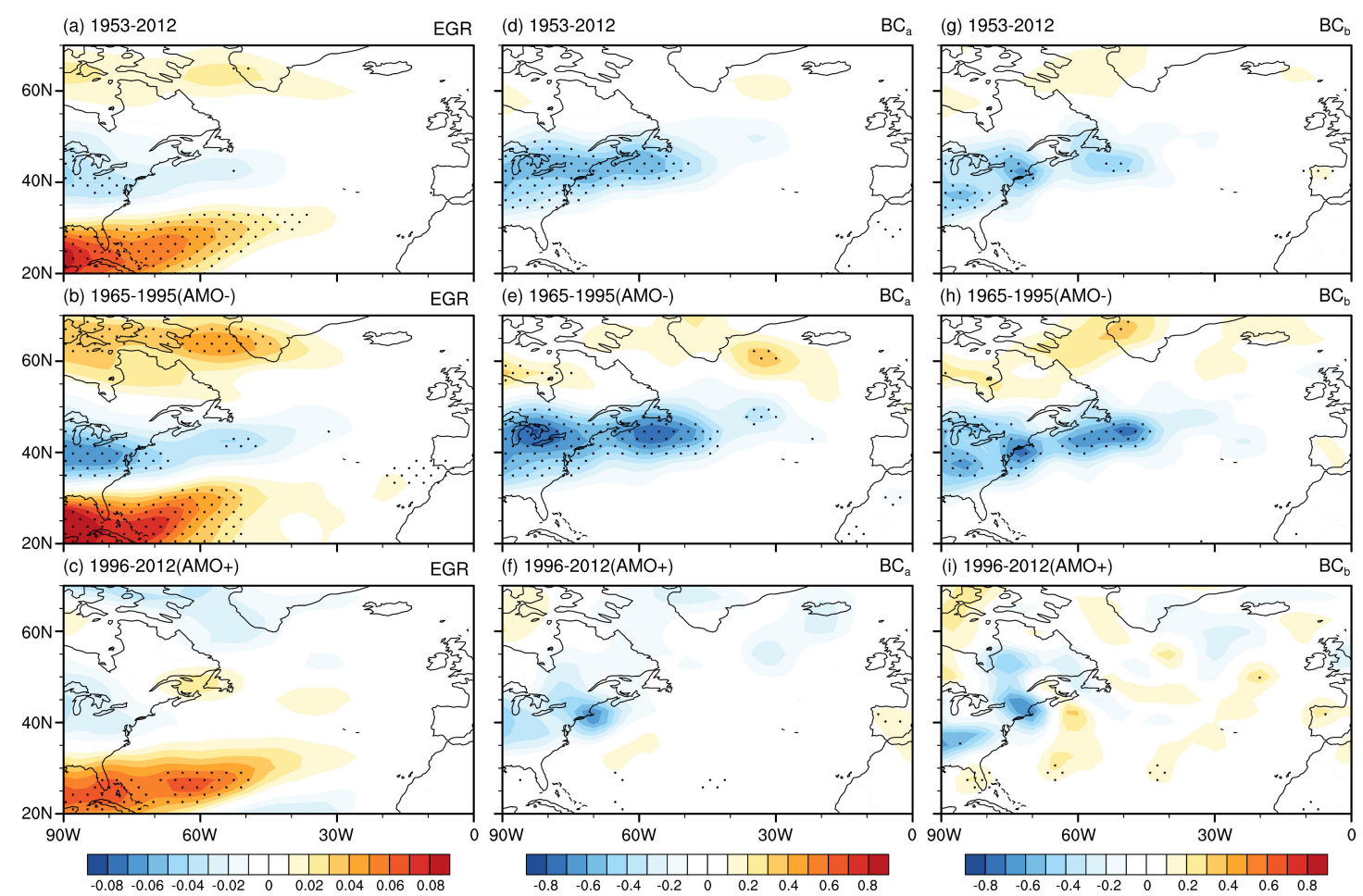

Figure 7. Regression coefficients of the maximum Eady growth rate (shading; units: day ${ }^{-1}$ ) at $700 \mathrm{hPa}$ onto the Niño3.4 index in spring during: (a) 1953-2012; (b) 1965-1995 (AMO-); and (c) 1996-2012 $(\mathrm{AMO}+)$. The same as $(\mathbf{a}-\mathbf{c})$, except for $\mathrm{BC}\left(\mathrm{W} / \mathrm{m}^{2}\right)$ : $(\mathbf{d}-\mathbf{f})$ from MAPE to EAPE $\left(\mathrm{BC}_{\mathrm{a}}\right)$; and $(\mathbf{g}-\mathbf{i})$ from EAPE to EKE $\left(\mathrm{BC}_{\mathrm{b}}\right)$. Stippling represents significance exceeding the $95 \%$ confidence level.

In addition, anomalous EGR and BC related to ENSO show distinguished spatial pattern in different AMO phases. During the negative AMO phase, a positive EGR anomaly in the high latitudes extends eastward from North Canada to southern Greenland, and a negative anomaly extends eastward to the Mid-Atlantic Ridge during an El niño event (Figure $7 \mathrm{~b}$ ). Correspondingly, both negative $\mathrm{BC}_{\mathrm{a}}$ and $\mathrm{BC}_{\mathrm{b}}$ anomalies in the mid latitudes stretch eastward to the Mid-Atlantic Ridge, and an obviously positive $\mathrm{BC}_{\mathrm{a}}$ anomaly appears southeast of Greenland (Figure 7e,h). Negative (positive) EGR and BC anomalies are also located upstream of the negative (positive) AST anomalies. During the positive AMO phase, no significant anomalies associated with the eddy energy occur in the mid and high latitudes (Figure 7c,f,i). Therefore, negative EGR and BC anomalies in the mid latitudes induce a weakened storm track activity south of the climatological AST, and positive anomalies in the high latitudes act to strengthen the storm track activity north of climatological AST, resulting in a northward shifted AST during an El Niño event in the negative AMO phase. In the positive AMO phase, 
ENSO-related change in the meridional location of the AST is insignificant due to the relatively small amplitude of EGR and BC anomalies.

\subsection{Results of Model Simulations}

Figure 8 compares the spring AST in the CTRL to that in the atmospheric reanalysis. In the CTRL, the spring AST is located over the North Atlantic Ocean, extending northwestward from the Great Lakes to the Northwest Atlantic, which is consistent with the reanalysis except for a relatively weaker and slightly eastward maximum center. According to Deng et al. [52] and Zhang et al. [53], the bias of the AST between the CTRL and the reanalysis is inevitable and acceptable in our simulation. Overall, the CAM5.1 shows a reasonable capability in simulating the climatological AST in spring.
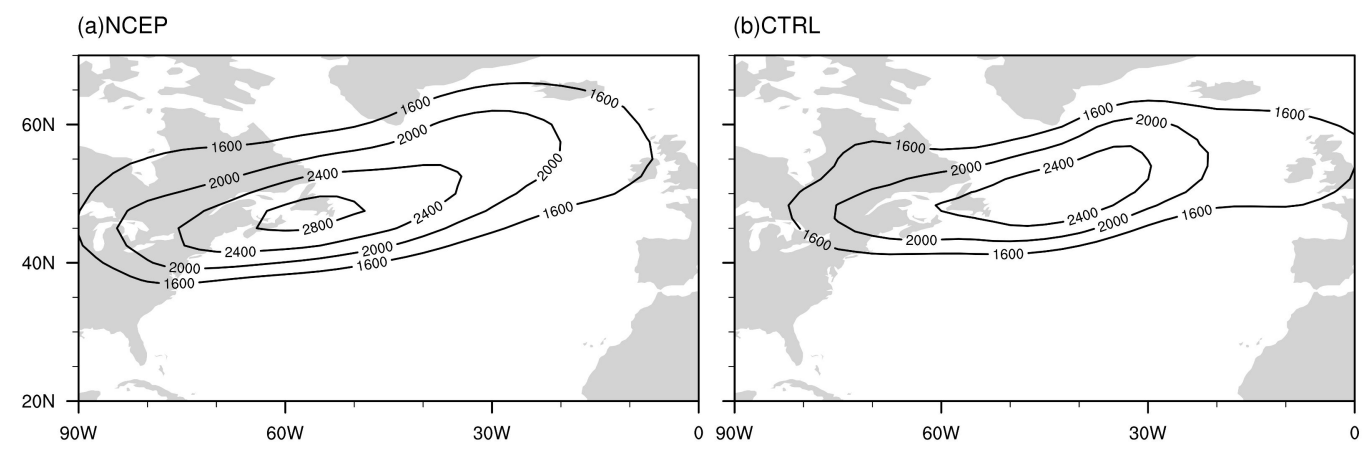

Figure 8. Climatological 500-hPa Atlantic storm track (contour; units: $\mathrm{m}^{2}$ ) in spring in: (a) the atmospheric reanalysis; and (b) CTRL. The contour interval is $400 \mathrm{~m}^{2}$.

The simulated responses of the spring AST to ENSO in different AMO phases are shown in Figure 9. Compared to the AMO-/La Niña experiment, a significantly northward shifted AST can be clearly seen in the AMO-/El Niño experiment (Figure 9a), which is consistent with the reanalysis (Figure 5b). In contrast, no obvious meridional shift of the AST is found due to ENSO in a positive AMO phase (Figure 9b). The responses of 500-hPa geopotential height also display a PNA-like pattern, which is consistent with the reanalysis (Figure 6). This anomalous wave train also propagates eastward and across the North American continent during El Niño in a negative AMO phase, with relatively large height anomalies over the North Atlantic (Figure 10a). The propagation of wave energy coincides with the spatial structure of the wave train. However, the ENSO-related anomalous wave train and wave energy only propagate northeastward to Northwest Canada, and is confined over the North Pacific and North America in a positive AMO phase (Figure 10b). Therefore, no significant height anomaly can be found over the downstream region. Next, the simulated differences of EGR and BC between El Niño and La Niña in negative and positive AMO phases are examined (Figure 11). The EGR in the negative AMO phase benefits negative anomalies over central North America extending eastward across North Atlantic and positive anomalies over Hudson Bay extending to Labrador Sea, corresponding to the northward shift of AST (Figure 11a). However, both negative and positive anomalies of EGR are relatively weak in the positive AMO phase (Figure 11b), which is consistent with the results from the reanalysis. Although the positive anomalies in extratropical are relatively weaker, the negative $\mathrm{BC}_{\mathrm{a}}$ and $\mathrm{BC}_{\mathrm{b}}$ anomalies in the negative $\mathrm{AMO}$ phase are still significantly stronger than those in the positive AMO phase (Figure 11c-f). Overall, the results from numerical experiments confirm the modulation of the AMO on the interannual relationship between ENSO and AST, in which ENSO-related changes of 500-hPa geopotential height play an important role. 
(a) AMO-/ El Niño - AMO-/ La Niña

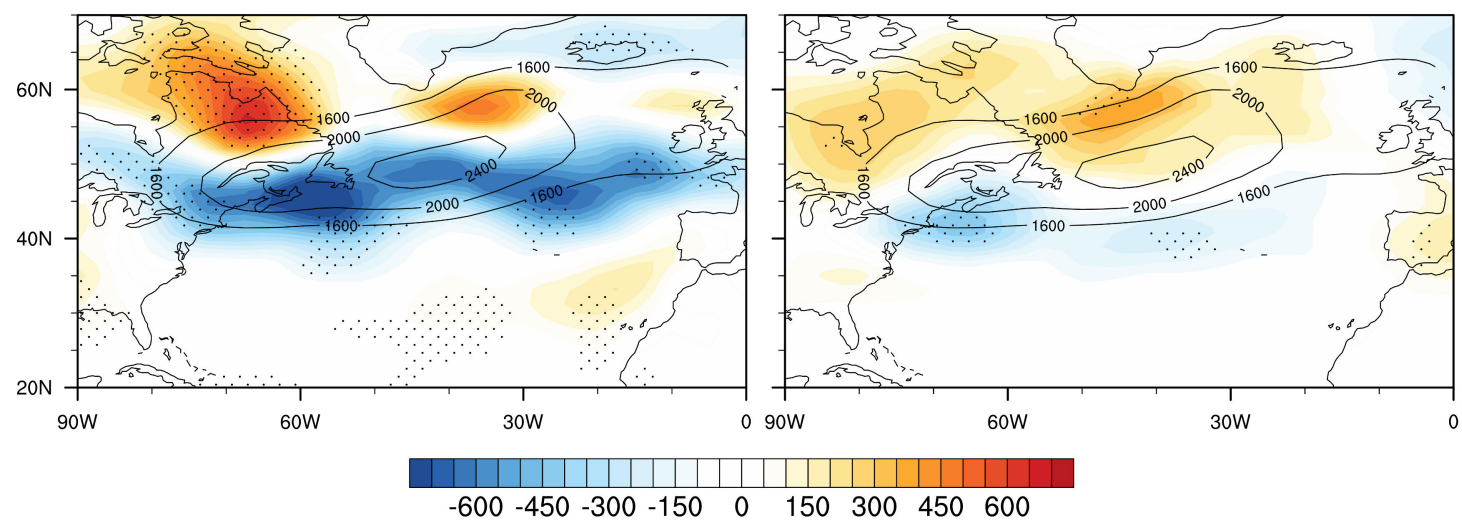

Figure 9. Simulated differences of the spring AST (shading; units: $\mathrm{m}^{2}$ ) in CAM5.1 between: (a) AMO-/El Niño and AMO-/La Niña; and (b) AMO+/El Niño and AMO+/La Niña. The contours represent the spring climatological AST in CTRL. Stippling represents significance exceeding the $95 \%$ confidence level.

(a) AMO-/ El Niño - La Niña

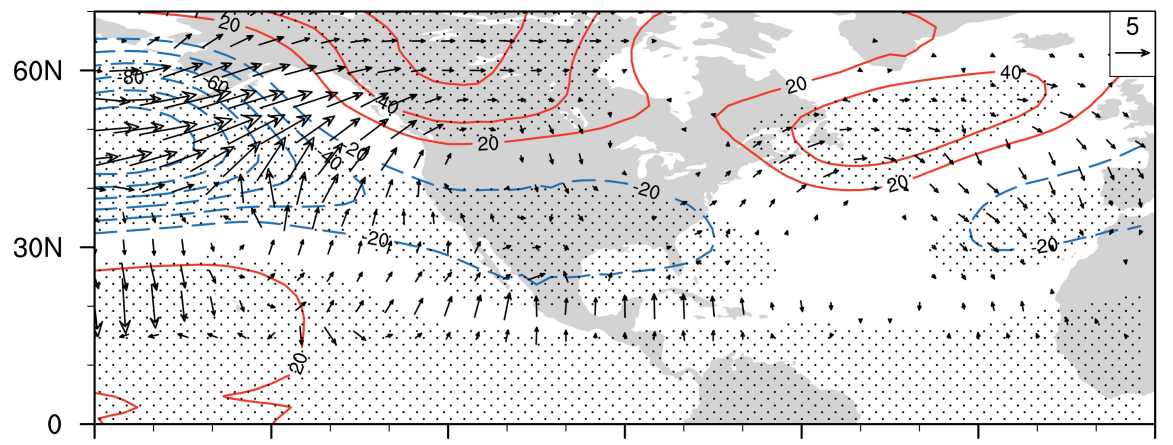

(b) $\mathrm{AMO}+$ / El Niño - La Niña

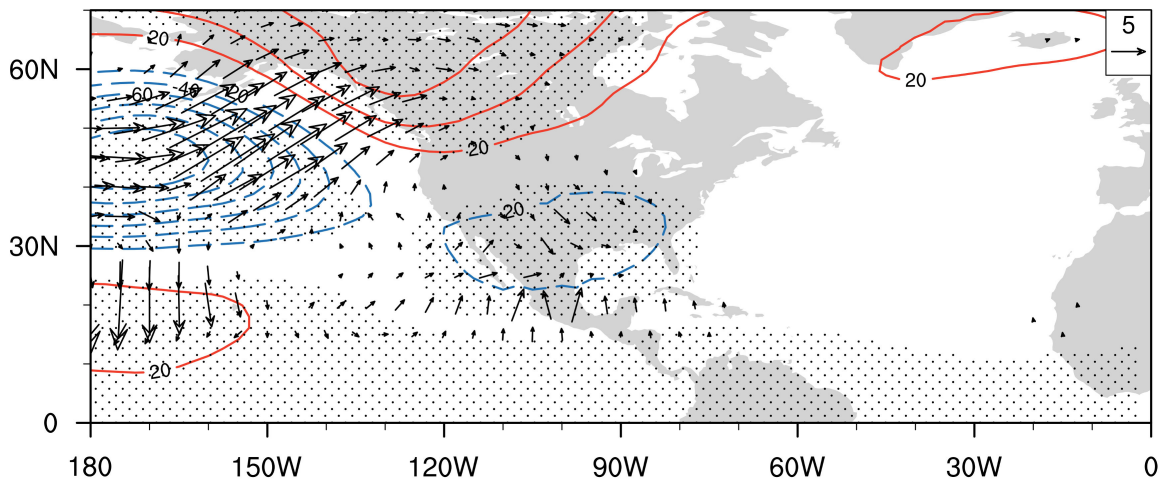

Figure 10. Same as Figure 9, except for differences of 500-hPa geopotential height (contour; units: gpm) in spring and the corresponding wave activity flux (vector; units: $\mathrm{m}^{2} / \mathrm{s}^{2}$ ). The red solid and blue dashed contours represent positive and negative values, respectively. The contour interval is 20 gpm, and the zero isoline is omitted for clarity. Only the WAF with its amplitude exceeding $0.5 \mathrm{~m}^{2} / \mathrm{s}^{2}$ is plotted. 

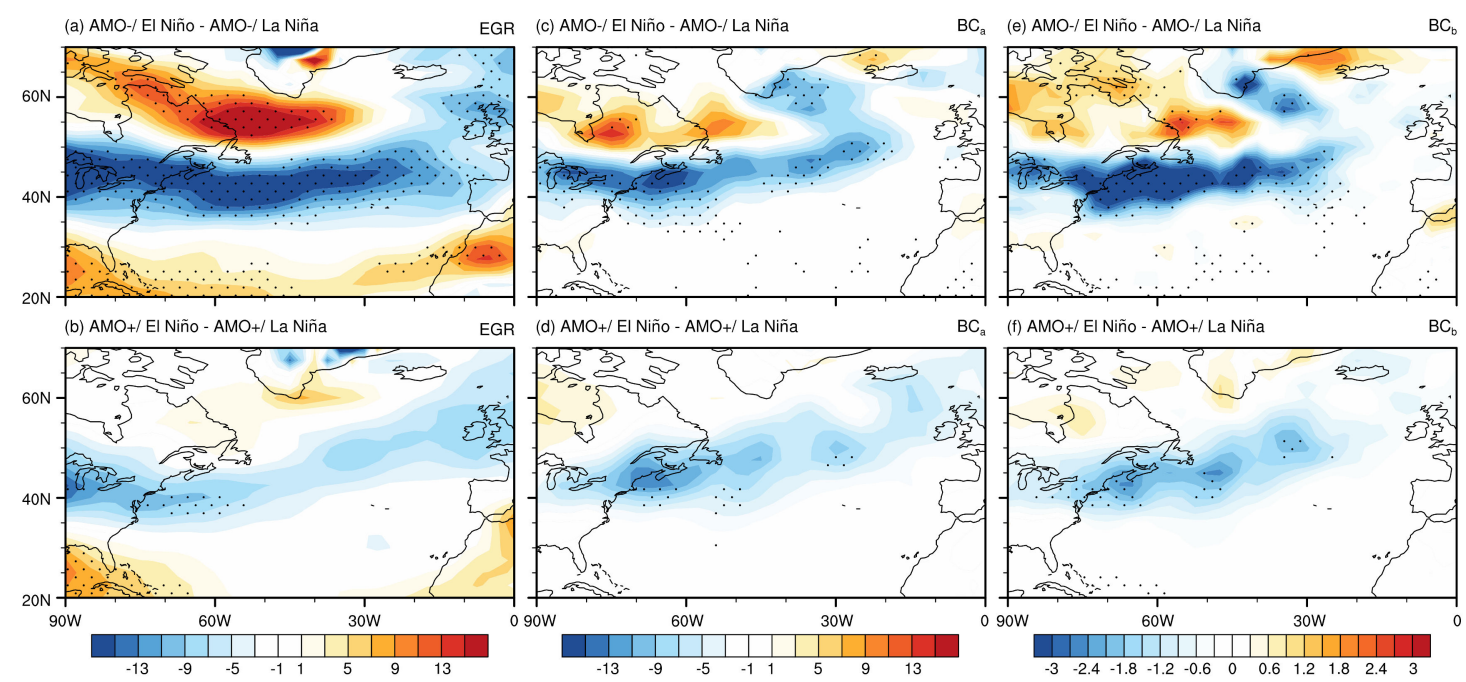

Figure 11. Same as Figure 9, except for: $(\mathbf{a}, \mathbf{b})$ the maximum Eady growth rate (EGR, shading; units: $10^{-2}$ day $\left.^{-1}\right)$; BC $(\mathbf{c}, \mathbf{d})$ from MAPE to EAPE $\left(\mathrm{BC}_{\mathrm{a}}\right.$, shading; units: $\left.\mathrm{W} / \mathrm{m}^{2}\right)$ and $(\mathbf{e}, \mathbf{f})$ from EAPE to EKE $\left(\mathrm{BC}_{\mathrm{b}}\right.$, shading; units: $\left.\mathrm{W} / \mathrm{m}^{2}\right)$ at $700 \mathrm{hPa}$.

\subsection{Summary and Directions of Future Work}

In this study, we explored possible processes of the decadal modulated ENSO-AST relationship by the AMO using both atmospheric reanalysis and model simulations from the perspective of ENSO-related atmospheric circulations. However, it is well known that the AMO cycle has a long periodicity of up to 70 years, while NCEP- 1 dataset only covers around one AMO cycle. The data span of atmospheric reanalysis may be a major source of uncertainty in this study. Therefore, long-term atmospheric reanalysis datasets (e.g., the 20th Century Reanalysis) and model simulations are needed to confirm our results in future work. Besides, ENSO can also exert an influence on the interannual variability of the Atlantic SST [54], which may further affect the AST activity. A fully coupled model, including the Atlantic SST response to ENSO, will be used in our future study to better understand the possible mechanism of decadal modulated ENSO-AST relationship.

\section{Conclusions}

The AMO exerts great influences on the spring ENSO-AST relationship via modulating the propagation of ENSO-related anomalous mid-tropospheric wave train. During an El Niño event in a negative AMO phase, the 500-hPa geopotential height anomalies associated with ENSO exhibit a PNA-like pattern, and the anomalous wave train propagates eastward until reaching the North Atlantic, which crosses the North American continent. Corresponding to the wave train pattern, the wave energy originated around the Niño3.4 region propagates poleward and eastward crossing the mid latitudes of the North Atlantic. Thus, a decreased (increased) westerly jet stream appears over central North America (North Canada). Meanwhile, the EGR and BC are decreased (increased) from central North America to the Mid-Atlantic Ridge (in the high latitudes). The westerly jet, EGR and BC are decreased (increased) upstream of the negative (positive) AST anomaly, weakening (strengthening) the southern (northern) part of the climatological AST. Therefore, the AST is shifted northward. In a positive AMO phase, however, the anomalous wave train only propagates northeastward to Northwest Canada, and the wave energy is largely suppressed there. No significant changes of the westerly jet, EGR and BC are found in the upstream region of the AST, resulting in insignificant change in the meridional location of the AST. The above reanalysis results are further confirmed by the CAM5.1 simulations.

In this paper, we demonstrate that the correlation between ENSO and the meridional location of the AST is significant in a negative AMO phase, while insignificant in a positive AMO phase. Studying the interannual relationship between ENSO and AST under different AMO phases will help us to 
understand the AST variability more comprehensively, which also provides a new idea for research on weather and short-term climate changes induced by the AST. To better understand the possible mechanism of ENSO-AST relationship modulated by the AMO, long-term atmosphere reanalysis datasets and a fully coupled model will be used in our future studies.

Author Contributions: Conceptualization, H.X.; methodology, H.X., C.L. and J.D.; software, C.L.; validation, C.L. and J.D.; formal analysis, C.L.; writing—original draft preparation, C.L., J.D. and L.Z.; writing-review and editing, C.L. and J.D.; and supervision, H.X.

Funding: This work was jointly supported by the Natural Science Foundation of China $(41575077,41490643$ and 41705054) and the Priority Academic Program Development of Jiangsu Higher Education Institutions (PAPD). Deng was supported by the Natural Science Foundation of Jiangsu Province (BK20170942) and the General Program of Natural Science Research of Jiangsu Province University (17KJB170012).

Conflicts of Interest: The authors declare no conflict of interest.

\section{References}

1. Blackmon, M.L. A climatological spectral study of the $500 \mathrm{mb}$ geopotential height of the northern hemisphere. J. Atmos. Sci. 1976, 33, 1607-1623. [CrossRef]

2. Lau, N.C. Variability of the observed midlatitude storm tracks in relation to low-frequency changes in the circulation pattern. J. Atmos. Sci. 1988, 45, 2718-2743. [CrossRef]

3. Chang, E.K.; Fu, Y. Interdecadal variations in Northern Hemisphere winter storm track intensity. J. Clim. 2002, 15, 642-658. [CrossRef]

4. Jin, F.F. Eddy-induced instability for low-frequency variability. J. Atmos. Sci. 2010, 67, 1947-1964. [CrossRef]

5. Kug, J.S.; Jin, F.F.; Park, J.; Ren, H.L.; Kang, I.S. A general rule for synoptic-eddy feedback onto low-frequency flow. Clim. Dyn. 2010, 35, 1011-1026. [CrossRef]

6. Nakamura, H.; Izumi, T.; Sampe, T. Interannual and decadal modulations recently observed in the Pacific storm track activity and East Asian winter monsoon. J. Clim. 2002, 15, 1855-1874. [CrossRef]

7. Nakamura, H. Midwinter suppression of baroclinic wave activity in the Pacific. J. Atmos. Sci. 1992, 49, 1629-1642. [CrossRef]

8. Christoph, M.; Ulbrich, U.; Speth, P. Midwinter suppression of Northern Hemisphere storm track activity in the real atmosphere and in GCM experiments. J. Atmos. Sci. 1997, 54, 1589-1599. [CrossRef]

9. Straus, D.M.; Shukla, J. Variations of midlatitude transient dynamics associated with ENSO. J. Atmos. Sci. 1997, 54, 777-790. [CrossRef]

10. Zhang, Y.; Held, I.M. A linear stochastic model of a GCM's midlatitude storm tracks. J. Atmos. Sci. 1999, 56, 3416-3435. [CrossRef]

11. Geng, Q.; Sugi, M. Variability of the North Atlantic cyclone activity in winter analyzed from NCEP-NCAR reanalysis data. J. Clim. 2001, 14, 3863-3873. [CrossRef]

12. Ebisuzaki, W.; Chelliah, M. ENSO and inter-decadal variability in storm tracks over North America and vicinity. In Proceedings of the 23d Annual Climate Diagnostics and Prediction Workshop, Miami, FL, USA, 26-30 October 1998.

13. Graham, N.E.; Diaz, H.F. Evidence for intensification of North Pacific winter cyclones since 1948. Bull. Am. Meteorol. Soc. 2001, 82, 1869-1894. [CrossRef]

14. Riviere, G.; Orlanski, I. Characteristics of the Atlantic storm-track eddy activity and its relation with the North Atlantic Oscillation. J. Atmos. Sci. 2007, 64, 241-266. [CrossRef]

15. Nie, J.; Wang, P.; Yang, W.; Tan, B. Northern hemisphere storm tracks in strong AO anomaly winters. Atmos. Sci. Lett. 2008, 9, 153-159. [CrossRef]

16. He, H.; Nie, J.; Tan, B. Northern hemisphere storm tracks in winter seasons and their energy budgets during the ENSO events. Acta Meteorol. Sin. 2009, 67, 210-217.

17. Paredes, D.; Trigo, R.M.; Garcia-Herrera, R.; Trigo, I.F. Understanding precipitation changes in Iberia in early spring: Weather typing and storm-tracking approaches. J. Hydrometeorol. 2006, 7, 101-113. [CrossRef]

18. Krishnamurthy, L.; Vecchi, G.A.; Msadek, R.; Wittenberg, A.; Delworth, T.L.; Zeng, F. The seasonality of the great plains low-level jet and ENSO relationship. J. Clim. 2005, 28, 4525-4544. [CrossRef]

19. Muñoz, E.; Enfield, D.B. The boreal spring variability of the Intra-Americas low-level jet and its relation with precipitation and tornadoes in the eastern United States. Clim. Dyn. 2011, 36, 247-259. [CrossRef] 
20. Lee, S.-K.; Mapes, B.E.; Wang, C.; Enfield, D.B.; Weaver, S.J. Springtime ENSO phase evolution and its relation to rainfall in the continental U.S. Geophys. Res. Lett. 2014, 41, 1673-1680. [CrossRef]

21. Zhang, Y.; Wallace, J.M.; Battisti, D.S. ENSO-like interdecadal variability: 1900-1993. J. Clim. 1997, 10, 1004-1020. [CrossRef]

22. Delworth, T.L.; Mann, M.E. Observed and simulated multidecadal variability in the Northern Hemisphere. Clim. Dyn. 2000, 16, 661-676. [CrossRef]

23. Kerr, R.A. A North Atlantic climate pacemaker for the centuries. Science 2000, 288, 1984-1985. [CrossRef] [PubMed]

24. Sutton, R.T.; Hodson, D.L. Atlantic Ocean forcing of North American and European summer climate. Science 2005, 309, 115-118. [CrossRef] [PubMed]

25. Zhou, Y.; Wu, Z. Possible impacts of mega-El Niño/Southern Oscillation and Atlantic Multidecadal Oscillation on Eurasian heatwave frequency variability. Q. J. R. Meteorol. Soc. 2016, 142, 1647-1661. [CrossRef]

26. Dong, B.; Sutton, R.T.; Scaife, A.A. Multidecadal modulation of El Nino-Southern Oscillation (ENSO) variance by Atlantic Ocean sea surface temperatures. Geophys. Res. Lett. 2006, 33. [CrossRef]

27. Kang, I.S.; No, H.H.; Kucharski, F. ENSO amplitude modulation associated with the mean SST changes in the tropical central Pacific induced by Atlantic multidecadal oscillation. J. Clim. 2014, 27, 7911-7920. [CrossRef]

28. Timmermann, A.; Okumura, Y.; An, S.I.; Clement, A.; Dong, B.; Guilyardi, E.; Hu, A.; Jungclaus, J.H.; Renold, M.; Stocker, T.F.; et al. The influence of a weakening of the Atlantic meridional overturning circulation on ENSO. J. Clim. 2007, 20, 4899-4919. [CrossRef]

29. Kalnay, E.; Kanamitsu, M.; Kistler, R.; Collins, W.; Deaven, D.; Gandin, L.; Zhu, Y. The NCEP/NCAR 40-year reanalysis project. Bull. Am. Meteorol. Soc. 1996, 77, 437-472. [CrossRef]

30. Huang, B.; Thorne, P.W.; Banzon, V.F.; Boyer, T.; Chepurin, G.; Lawrimore, J.H.; Zhang, H.M. NOAA Extended Reconstructed Sea Surface Temperature (ERSST), Version 5; NOAA National Centers for Environmental Information: Boulder, CO, USA, 2017.

31. Blackmon, M.L.; Wallace, J.M.; Lau, N.C.; Mullen, S.L. An observational study of the northern hemisphere wintertime circulation. J. Atmos. Sci. 1977, 34, 1040-1053. [CrossRef]

32. Barnston, A.G.; Chelliah, M.; Goldenberg, S.B. Documentation of a highly ENSO-related SST region in the Equatorial Pacific. Atmos.-Ocean 1997, 35, 367-383. [CrossRef]

33. Enfield, D.B.; Mestas-Nunez, A.M.; Trimble, P.J. The Atlantic Multidecadal Oscillation and its relationship to rainfall and river flows in the continental U.S. Geophys. Res. Lett. 2001, 28, 2077-2080. [CrossRef]

34. Duchon, C.E. Lanczos filtering in one and two dimensions. J. Appl. Meteor. 1979, 18, 1016-1022. [CrossRef]

35. Duchon, C.; Hale, R. Time Series Analysis in Meteorology and Climatology: An Introduction; John Wiley \& Sons: Hoboken, NJ, USA, 2012; Volume 7.

36. Yao, J.X.; Li-Ping, L.I.; Luo, X.; Yang, W.; Wang, P.X. Lanczos filter suitable for filtering quasi-two-week and quasi-one-month oscillations and its applications. Trans. Atmos. Sci. 2012, 35, 221-228.

37. Anderson, D.; Hodges, K.I.; Hoskins, B.J. Sensitivity of feature-based analysis methods of storm tracks to the form of background field removal. Mon. Weather Rev. 2003, 131, 565-573. [CrossRef]

38. Woolnough, S.J.; Slingo, J.M.; Hoskins, B.J. The relationship between convection and sea surface temperature on intraseasonal timescales. J. Clim. 2000, 13, 2086-2104. [CrossRef]

39. Lee, S. Barotropic effects on atmospheric storm tracks. J. Atmos. Sci. 2000, 57, 1420-1435. [CrossRef]

40. Lindzen, R.S.; Farrell, B. A simple approximate result for the maximum growth rate of baroclinic instabilities. J. Atmos. Sci. 1980, 37, 1648-1654. [CrossRef]

41. Cai, M.; Yang, S.; Dool, H.M.V.D.; Kousky, V.E. Dynamical implications of the orientation of atmospheric eddies: A local energetics perspective. Tellus A 2007, 59, 127-140. [CrossRef]

42. Takaya, K.; Nakamura, H. A formulation of a phase-independent wave-activity flux for stationary and migratory quasigeostrophic eddies on a zonally varying basic flow. J. Atmos. Sci. 2001, 58, 608-627. [CrossRef]

43. Neale, R.B.; Chen, C.C.; Gettelman, A.; Lauritzen, P.H.; Park, S.; Williamson, D.L.; Marsh, D.; Liu, X.; Conley, A.J.; Taylor, M.A.; et al. Description of the NCAR Community Atmosphere Model (CAM 5.0); NCAR Tech. Note NCAR/TN-486+ STR; NCAR: Boulder, CO, USA, 2010.

44. Ruprich-Robert, Y.; Msadek, R.; Castruccio, F.; Yeager, S.; Delworth, T.; Danabasoglu, G. Assessing the climate impacts of the observed Atlantic multidecadal variability using the GFDL CM2. 1 and NCAR CESM1 global coupled models. J. Clim. 2017, 30, 2785-2810. [CrossRef] 
45. Quadrelli, R.; Bretherton, C.S.; Wallace, J.M. On Sampling Errors in Empirical Orthogonal Functions. J. Clim. 2005, 18, 3704-3710. [CrossRef]

46. North, G.R.; Bell, T.L.; Cahalan, R.F.; Moeng, F.J. Sampling errors in the estimation of empirical orthogonal functions. Mon. Weather Rev. 1982, 110, 699-706. [CrossRef]

47. Lee, S.S.; Lee, J.Y.; Wang, B.; Ha, K.J.; Heo, K.Y.; Jin, F.F.; Straus, D.M.; Shukla, J. Interdecadal changes in the storm track activity over the North Pacific and North Atlantic. Clim. Dyn. 2012, 39, 313-327. [CrossRef]

48. Metz, W. Low-frequency anomalies of atmospheric flow and the effects of cyclone-scale eddies: A canonical correlation analysis. J. Atmos. Sci. 1989, 46, 1026-1041. [CrossRef]

49. Penny, S.M.; Battisti, D.S.; Roe, G.H. Examining mechanisms of variability within the Pacific storm track: Upstream seeding and jet-core strength. J. Clim. 2013, 26, 5242-5259. [CrossRef]

50. Pinto, J.G.; Reyers, M.; Ulbrich, U. The variable link between PNA and NAO in observations and in multi-century CGCM simulations. Clim. Dyn. 2011, 36, 337-354. [CrossRef]

51. Hoskins, B.J.; Valdes, P.J. On the existence of storm-tracks. J. Atmos. Sci. 1990, 47, 1854-1864. [CrossRef]

52. Deng, J.; Xu, H.; Ma, H.; Jiang, Z. Numerical study of the effect of anthropogenic aerosols on spring persistent rain over eastern China. J. Meteor. Res. 2014, 28, 341-353. [CrossRef]

53. Zhang, L.; Xu, H.; Shi, N.; Deng, J. Responses of the East Asian jet stream to the North Pacific subtropical front in spring. Adv. Atmos. Sci. 2017, 34, 144-156. [CrossRef]

54. Saravanan, R.; Chang, P. Interaction between tropical Atlantic variability and El Nino-Southern Oscillation. J. Clim. 2000, 13, 2177-2194. [CrossRef]

(C) 2018 by the authors. Licensee MDPI, Basel, Switzerland. This article is an open access article distributed under the terms and conditions of the Creative Commons Attribution (CC BY) license (http://creativecommons.org/licenses/by/4.0/). 